\title{
LA RECAUDACIÓN FISCAL \\ EN EL MUNDO RURAL \\ DE LA RESTAURACIÓN: \\ OBSTÁCULOS Y RESISTENCIAS *
}

\author{
RICARD GARCÍA ORALLO \\ Universitat de Girona
}

\begin{abstract}
RESUMEN
Este artículo estudia los procedimientos usados por la Hacienda pública española para afrontar los débitos por contribuciones e impuestos durante las últimas décadas del siglo XIX y primeras del XX. Utilizando el testimonio de los recaudadores de impuestos, se analizan las relaciones entre las diferentes instituciones implicadas y entre éstas y los contribuyentes. La gran cantidad de fincas embargadas por el Estado por deudas fiscales son un síntoma de las transformaciones que el campo español estaba experimentando. Este fenómeno se convirtió en una importante fuente de conflictos y puso en evidencia algunos de los problemas estructurales de la Administración de la Restauración.
\end{abstract}

\section{ABSTRACT}

This article studies the proceedings used by the Spanish public finances to deal with the unpaid taxes during the last decades of the 19th century and the beginning of the $20 \mathrm{th}$. The connections between the concerned public institutions, and between these and the taxpayers, are analysed using the statements of tax collectors. The great amount of land seized by the State, as a consequence of unpaid taxes, are a sign of the changes that the Spanish rural areas were suffering. This phenomenon became a serious source of con-

* Agradezco los comentarios y sugerencias de Rosa Congost, Enric Saguer y de los evaluadores de la Revista de Historia Económica; así como los de Josep Fontana y Antonio López Estudillo, miembros del tribunal que juzgó el trabajo presentado al programa de doctorado de la Universitat de Girona, que ha dado lugar a este texto. 
flict and it made evident the important structural problems of the Restauration Administration.

JEL Classification: H22, H31, N43, N53.

\section{INTRODUCCIÓN}

En tanto que pieza clave en la cuenta de ingresos de un Estado permanentemente amenazado por el déficit presupuestario, la cuestión fiscal ocupó un lugar central entre las preocupaciones de los gobiernos españoles de las últimas décadas del siglo XIX. En ese mismo período, el sistema tributario español se convirtió en un objetivo recurrente de las protestas de amplios sectores de la población, especialmente en el ámbito rural, condicionando en gran medida las relaciones entre el Estado y la sociedad civil. El objeto del presente texto es ahondar en la problemática fiscal de la España de la Restauración y particularmente en la práctica fiscal de la etapa comprendida entre 1875 y los primeros años del siglo XX. El estudio se centrará de forma especial en la fase ejecutiva de la recaudación de impuestos, para lo cual se recurrirá al testimonio de quienes la tenían encomendada, puesto que los obstáculos que recaudadores y agentes ejecutivos hallaban en el desempeño de su trabajo reflejan algunos de los principales problemas estructurales de la Administración española. Su cometido los convirtió, además, en testigos privilegiados de la sociedad rural de la época, de la precaria situación de muchos campesinos y de los desequilibrios sociales del campo español.

Aunque es difícil estimar de forma precisa la presión fiscal soportada por la agricultura española del período, la evolución de las cifras globales y, quizás con mayor claridad, de las que se desprenden de las diversas contabilidades privadas que han sido estudiadas, parece evidenciar que la fracción de la renta agraria dedicada a afrontar las obligaciones fiscales aumentó de forma significativa a partir de $1875^{1}$. Los datos hacen patente, además, la desproporción entre el esfuerzo que el Estado demandaba al sector agropecuario y el asumido por el resto de sectores económicos ${ }^{2}$.

La Contribución de inmuebles, cultivo y ganadería, que recaía principalmente scbre la propiedad rústica y las explotaciones agrarias, constituyó, con gran diferencia, la principal fuente de ingresos ordinarios para el Estado durante la segunda mitad del siglo XIX. Entre 1875 y 1900, tanto

\footnotetext{
${ }^{1}$ Garrabou, Planas y Saguer (2001); Pascual (2000).

2 Vallejo (2001), p. 359.
} 
el tipo oficial de gravamen como las cifras absolutas de su recaudación se incrementaron apreciablemente ${ }^{3}$. Pero a la carga que representaba la contribución territorial para muchas explotaciones familiares, sobre todo para aquellos pequeños propietarios que asumían íntegramente su pago, se añadían diversos recargos municipales, provinciales y estatales que podían alcanzar cuantías en absoluto desdeñables. A su vez, los cupos correspondientes al impuesto de consumos, segundo tributo en importancia y teóricamente de tipo indirecto, eran habitualmente repartidos entre los contribuyentes vecinos de cada municipio en proporción, principalmente, a la cuota satisfecha por contribución territorial, convirtiéndose para una fracción muy importante de la población rural en una segunda imposición directa que, además, era también sistemáticamente recargada ${ }^{4}$. Aplazada repetidamente la reforma global del sistema fiscal que muchas opiniones autorizadas reclamaban, y en la que la tantas veces postergada elaboración de un catastro parcelario hubiera sido una pieza esencial, una de las líneas estratégicas seguidas por los sucesivos ministros de Hacienda se orientó hacia el deseado perfeccionamiento de los mecanismos administrativos de la Hacienda pública. Ya desde los primeros años de la década de 1880, bajo la gestión del ministro Juan Francisco Camacho, se dio prioridad, junto a la lucha contra la ocultación, al aumento de la rigurosidad en la recaudación ${ }^{5}$.

El despliegue paulatino de la maquinaria recaudatoria y la mejora relativa de su eficacia coincidieron en el tiempo con la llamada crisis agraria finisecular. El descenso generalizado de los precios de los productos agrícolas a partir de la década de 1880 y, algo más tarde, la irrupción de la filoxera en el sector vitivinícola ajustaron los márgenes de beneficio de las familias campesinas, dejando al descubierto la importancia relativa de la presión fiscal en sus cuentas de explotación. Así parecen indicarlo síntomas como el progresivo desajuste entre las cantidades presupuestadas y las efectivamente recaudadas, la cada vez más presente conflictividad fiscal, tanto pasiva como violenta, o el aumento exponencial del número de deudores a la Hacienda.

Este último elemento se tradujo en una cantidad espectacular de fincas embargadas, subastadas y finalmente adjudicadas al Estado por deudas

${ }_{4}^{3}$ La evolución de las cifras en Comín (1988) y Vallejo (2001).

4 Pan-Montojo (1994); Vailejo (1996). En 1887 el 66,5 por 100 de los 9.982 municipios españoles recaudaban el impuesto de consumos mediante reparto; en 1900 eran todavía el 39,3 por 100 de los 11.322 ayuntamientos existentes (Vallejo, 1998, p. 94).

${ }^{5}$ Vallejo (1999), pp. 59 y 64; Martorell (2000), pp. 54-55. 
tributarias, cuestión que provocó, a tenor de los testimonios, una considerable alarma social entre los sectores afectados, además de la perplejidad de destacados intelectuales ${ }^{6}$. A pesar del casi absoluto desconocimiento estadístico sobre el alcance real del problema del que hacían gala los ministros de Hacienda, el orden de magnitud de las cifras barajadas, sobre todo durante la década de los noventa, no puede dejar de sorprender ${ }^{7}$. Los cientos de miles de subastas por impago de las contribuciones directas pueden ser vistas, más allá del fraude estructural que pudiera explicarlas parcialmente, como un indicador - si no la causa- del empeoramiento de las condiciones de vida de un número no despreciable de contribuyentes ${ }^{8}$.

\section{LOS MECANISMOS DE LA RECAUDACIÓN EJECUTIVA: LA INSTRUCCIÓN DE 1888}

El procedimiento aplicado por la Hacienda pública para el cobro de deudas por contribuciones e impuestos sufrió diversos cambios durante el último cuarto del siglo XIX y las primeras décadas del XX. Cuatro Instrucciones y una larga sucesión de disposiciones de menor entidad establecieron o modificaron puntualmente diferentes aspectos del proceso, complicando aún más una ya de por sí compleja legislación fiscal. El instrumento normativo más representativo del período fue la Instrucción para el procedimiento contra deudores a la Hacienda, promulgada por el Real Decreto de 12 de mayo de 1888, tras la asunción por la Hacienda pública de la recaudación de las contribuciones directas, al no prorrogarse el convenio existente con el Banco de España 9

' Por ejemplo, Mallada (1969) o Pazos (1908).

${ }^{7}$ La cifra más citada es la de 199.311 fincas adjudicadas al Estado entre 1880 y 1886, recogida por La Crisis Agricola y Pecuaria (vol. 8, p. 571). En 1890, sin embargo, se discutía en el Congreso de Diputados en torno a las 610.428 fincas supuestamente adjudicadas a la Hacienda hasta diciembre de 1888 (Boletin de la Recaudación, 8 de junio de 1890) y la Gaceta Agricola del Ministerio de Fomento (1 ${ }^{\text {er }}$ trimestre de 1891 , p. 503) daba noticia de 1.982 .475 subastas celebradas entre 1874 y 1890 , de las que 942.561 habrían resultado estériles. Este último balance fue mal interpretado por Sánchez Asensio (1926, p. 156), proporcionando una cifra errónea de subastas, casi cuatro millones, que ha sido también muy citada. Sobre la ignorancia estadística de los gobiernos: Diario de Sesiones del Congreso, 5 de julio de 1878 , pp. 2759 ss.

${ }^{8} \mathrm{Y}$ así lo han señalado autores como Calatayud (1989), p. 78; Garrabou (1975), p. 210; Fontana (1975); Germán y Forcadell (1988), p. 85; Giralt (1990), p. 159; o Pérez Picazo (1996), p. 15.

${ }^{9}$ La nueva Instrucción actualizó la promulgada el 20 de mayo de 1884 y fue sustituida por la decretada el 26 de abril de 1900 . 
La Instrucción de 12 de mayo de 1888 concedió a los recaudadores la condición de empleados públicos, bajo la directa dependencia de las delegaciones de Hacienda, haciendo explícita por primera vez la obligatoriedad de encargar a personas distintas la recaudación durante la fase voluntaria, llevada a cabo por recaudadores, y la tramitación de los apremios, encomendada a agentes ejecutivos. Se resolvía así un aspecto que había resultado controvertido ${ }^{10}$. Unos y otros, ayudados por tantos auxiliares como creyesen oportuno, debían presentar trimestralmente a la Administración económica provincial las correspondientes liquidaciones. La legalidad de sus actuaciones y los capitales que manejaban quedaban garantizados con las fianzas que habían depositado en el momento de su nombramiento.

Cumplido el período previsto para el pago voluntario de cada una de las cuotas trimestrales en que se dividían los importes anuales de la Contribución de inmuebles, cultivo y ganadería o de la Industrial y de comercio, los contribuyentes deudores quedaban afectados por el apremio de primer grado y un recargo del 5 por 100 sobre el total del recibo pendiente, iniciándose así la fase ejecutiva. Pasados tres días, cinco en las capitales de provincia, el agente ejecutivo decretaba el apremio de segundo grado para las deudas todavía no satisfechas, imponía el recargo correspondiente ( 7 por 100 sobre la cuota original) y mandaba proceder al embargo, valoración y subasta de los bienes muebles, animales, frutos y rentas cuya venta pudiese enjugar el débito.

Tras la celebración de las subastas, los agentes ejecutivos debían proporcionar a las juntas periciales listas de los contribuyentes aún deudores para que las cantidades pendientes fuesen clasificadas como partidas fallidas, cuando el apremiado carecía de inmuebles embargables, o cobrables. En el primer caso, tras la revisión y aprobación por parte de la Autoridad económica de la provincia, las cuotas correspondientes eran dadas de baja en el repartimiento del siguiente año y se redistribuían entre el resto de contribuyentes del municipio en virtud del principio de solidaridad colectiva establecido para el pago de los cupos. En el caso de las declaradas cobrables, se debía incluir una certificación de los datos que constasen en los amillaramientos y demás documentos disponibles sobre las fincas que se con-

${ }^{10}$ Habían sido habituales las denuncias contra recaudadores que ralentizaban conscientemente el cobro de las cuotas para así poder entrar en periodo ejecutivo y optar a los premios de cobranza, equivalentes al importe de los recargos (Vallejo, 1998, p. 585). Sin embargo, la Ley de presupuestos de 30 de junio de 1892 volvió a decretar la unificación de ambos cargos y lo mismo se dispuso en la Instrucción de 26 de abril de 1900. 
siderasen adecuadas para afrontar el descubierto de cada deudor, pudiéndose así iniciar el apremio de tercer grado. Se aplicaba entonces un nuevo recargo del 8 por 100 sobre la cuota originalmente adeudada, se expedían los mandamientos para la anotación preventiva del embargo en el Registro de la propiedad y se procedía a la valoración de los inmuebles mediante la capitalización - al 5 por 100 , si eran rústicas, o al 4 por 100 , en el caso de las urbanas- del líquido imponible con que figuraban en los amillaramientos. Seguidamente se señalaba la fecha, con un mínimo de quince días de antelación, en la que tendría lugar la subasta, cuyo anuncio debía de publicarse en el Boletín Oficial de la Provincia, en el caso de capitales de provincia, o mediante edictos y otros «medios usuales» en el resto de municipios.

De no presentarse licitadores a la primera subasta, se convocaba una segunda en los inmediatos días, con el valor de salida de las fincas rebajado en una tercera parte. Si ésta también era declarada desierta, los inmuebles eran puestos a disposición del ayuntamiento para que, previo pago de las cuotas, recargos y costas, gestionase su venta o arrendamiento. En el caso de ser rechazadas por el ayuntamiento, el agente ejecutivo adjudicaba las fincas a la Hacienda, que debía hacerse cargo de los gastos y tramitar su incautación e inventariado para posteriormente ponerlas en venta en la forma establecida para el resto de bienes del Estado. Si, por el contrario, alguna finca encontraba comprador en una de las dos subastas, se procedía a otorgar escritura pública de venta por parte del deudor, o del agente ejecutivo si el primero se negaba, liquidándose la deuda y entregando al deudor el sobrante, si lo hubiese. Las ambigüedades en el redactado, los casos no previstos por las Instrucciones o, simplemente, los problemas derivados de la práctica cotidiana, dieron lugar, durante todo el período, a una abundante legislación complementaria que incidió, a veces de forma importante, sobre la normativa establecida.

\section{OBSTÁCULOS Y RESISTENCIAS A LA RECAUDACIÓN: EL PUNTO DE VISTA DE LOS RECAUDADORES Y AGENTES EJECUTIVOS}

El colectivo de recaudadores y agentes ejecutivos ocupaba una posición marginal en el organigrama general de la Administración. Esta circunstancia se hacía aún más evidente cuando pertenecían a compañías arrendatarias 
privadas, cuyo número iba en aumento ${ }^{11}$. Unido a ello, su ausencia en los procesos de negociación que se entablaban entre las diversas esferas del poder para las asignaciones de los cupos provinciales y municipales, y de las cuotas individuales, les confería una cierta independencia y libertad de crítica a la hora de emitir opiniones, tanto en lo que hacía referencia a contribuyentes y ayuntamientos, como en lo relacionado con el aparato administrativo general, con la propia maquinaria de Hacienda y con la labor del Ministerio que se expresaba a través de las leyes, reglamentos y circulares.

Entre la prensa económica de diversa índole aparecida durante la Restauración, al menos tres cabeceras estuvieron específicamente dirigidas al colectivo de recaudadores y agentes ejecutivos. La Gaceta de la Recaudación (en adelante GR), el Boletín de la Recaudación (BR) y la Gaceta de Contribuciones fueron tres publicaciones bastante similares que se ocuparon de forma monográfica de las cuestiones relacionadas con la recaudación de contribuciones ${ }^{12}$. Estas revistas nos ofrecen una perspectiva hasta cierto punto inédita desde la cual observar aspectos muy diversos relacionados con la vertiente más práctica de la fiscalidad.

Bajo la consideración implícita de que la recaudación de los cupos estipulados constituía el principal y casi único objetivo de la comunidad de recaudadores y agentes ejecutivos, sus textos muestran de forma clara un corporativismo incipiente de claro carácter defensivo y un apoliticismo que se quería neutral y que sólo se rompía para atacar a los grupos políticos que en un momento $\mathrm{u}$ otro fomentaron la resistencia fiscal, como sucedió durante las campañas impulsadas en los últimos años del siglo por la Unión Nacional.

La sacralización de los cupos, jamás cuestionados, se materializaba en una actitud abiertamente pragmática a la hora de afrontar la tarea encomendada. Una actitud que se ponía en evidencia, como veremos, en las críticas y sugerencias que se hacían a propósito de una reglamentación considerada la mayor parte de las veces excesivamente rígida, cuando no ambigua, contradictoria o, directamente, absurda. No eran infrecuentes las recomendaciones al colectivo de obviar algunos de los trámites o de

1 En 1900 había 17 provincias en las que el cobro de las contribuciones directas corría a cargo de arrendatarios (Boletín de la Recaudación, 8 de noviembre de 1900); en 1908 eran ya 36 (Boletín de la Recaudación, 8 de febrero de 1908).

${ }_{12}$ El primer número de la Gaceta de la Recaudación vio la luz el 8 de julio de 1884; el último está ferhado el 30 de junio de 1889 . El 8 de julio de 1889 apareció el Boletín de la Recaudación, considerado la continuación de la Gaceta. 
cumplirlos de una forma más flexible de lo que las Instrucciones exigían. Consecuentemente, el contexto económico y social aparece en este tipo de literatura únicamente cuando representaba un obstáculo para la recaudación de los cupos. En unos textos que tienden a ensimismarse en una problemática administrativa específica, la «realidad» es habitualmente utilizada como excusa para explicar los descensos en la recaudación experimentados en determinados momentos.

\subsection{La recaudación ejecutiva y el poder local}

Su ya comentada marginalidad respecto de la estructura administrativa del Estado y la considerable autonomía de acción de que disponían llevaban a menudo a recaudadores y agentes ejecutivos a chocar con aquellas instituciones con las que mantenían un mayor contacto: los ayuntamientos, los Registros de la propiedad y las propias administraciones provinciales de Hacienda.

A pesar de los intentos legislativos encaminados a delimitar claramente las competencias de las diversas administraciones, las ambigüedades de los textos y las inercias históricas dejaron en manos de los consistorios municipales y de los poderes económicos locales, a través de su participación conjunta en las juntas periciales, gran parte de la gestión de varios impuestos. Por otra parte, así como el impuesto de consumos era percibido como una responsabilidad exclusiva de los ayuntamientos, en tanto que lo gestionaban casi por completo y dependían financieramente de él, las características de la contribución territorial ofrecían a éstos numerosas oportunidades de presentarse, sobre todo en momentos de dificultades generalizadas, como defensores frente al Estado de los intereses comunes del municipio, reforzando el tradicional papel intermediador desempeñado por las élites locales ${ }^{13}$. La tarea de los ayuntamientos relacionada con la Contribución de inmuebles, cultivo y ganadería no se limitaba a la confección puntual de las cartillas evaluatorias o de los repartimientos anuales, o a su participación en las negociaciones para establecer el cupo ${ }^{14}$. Además de encargarse íntegramente de la recaudación cuando el Banco de España (entre 1868 y 1888) o la administración de Hacienda (a partir de 1888)

${ }^{13}$ La Hacienda Nacional (15 de octubre de 1901) reivindicaba la plena recuperación del carácter estatal del impuesto de consumos y exigía aumentar el control del Estado sobre la calidad y rigurosidad de la gestión llevada a cabo por arrendatarios y ayuntamientos.

${ }_{14}$ Pro (1994), Vallejo (2001), López Estudillo (2000), Diaz Marín (2000). 
no podían cubrir todas las plazas de recaudadores o agentes ejecutivos, circunstancia que se dio con bastante frecuencia, las corporaciones municipales dispusieron durante todo el periodo de un amplio abanico de posibilidades de intervención ${ }^{15}$. Las constantes quejas de los recaudadores a lo largo de las últimas décadas del siglo $\mathrm{XIX}$ y las primeras del $\mathrm{XX}$ parecen demostrar que, lejos de solucionarse con las modificaciones legislativas que se iban introduciendo, la situación no hizo más que agravarse.

El retraso injustificado de los ayuntamientos en la confección de las certificaciones de fincas embargables o, en su caso, de la declaración de partidas fallidas, fue una de denuncias más repetidas por parte de los agentes ejecutivos. Era hasta cierto punto comprensible el incremento de trabajo que suponía para los secretarios municipales la multiplicación de los apremios, sobre todo en los distritos más pequeños en los que las «mezquinas dotaciones» y el «cúmulo tal de servicios» hacía imposible la realización acertada y oporiuna de los servicios ${ }^{16}$. Pero la lentitud en la tramitación era habitualmente atribuida a la voluntad expresa de los alcaldes de paralizar mientras fuese posible el embargo de las fincas, al tiempo que el de los frutos y cosechas se hacía imposible por desconocerse su ubicación ${ }^{17}$. Ese mismo sentido podía tener la exigencia a los agentes ejecutivos del cumplimiento de trámites que, si bien estaban previstos en las instrucciones, no siempre podían ser llevados a la práctica. La imposibilidad, por ejemplo, de cumplir con el preceptivo embargo de animales, probablemente ocultos, permitía al alcalde negarse a certificar las fincas ${ }^{18}$.

Los datos erróneos o imprecisos en las relaciones de fincas a embargar suponían también un grave problema. Muchas veces era una consecuencia de la deficiente información contenida en los amillaramientos y sus apéndices, de su falta de actualización o, en ocasiones, de su inexistencia ${ }^{19}$. En otros casos, sin embargo, las listas mal confeccionadas parecían obedecer de forma clara a una actitud fraudulenta ${ }^{20}$. Al igual que el incumplimiento de los plazos, la consignación de datos ambiguos o poco detallados sobre

1s Una estadística presentada al Congreso en 1890 cifraba en 1.999 los ayuntamientos "encargados de la recaudación de las contribuciones territorial é industrial por falta de recaudadores» (BR, 8 de junio de 1890 ).

16 $B R, 23$ de junio de 1890 .

$17 \mathrm{BR}, 31$ de octubre de 1904; GR, 28 de febrero de 1885 , o $G R, 15$ de diciembre de 1886 , por ejemplo. Las penalizaciones a los ayuntamientos previstas en caso de retrasos, en opinión del $B R$, ni eran suficientes ni se ponían en práctica.

is $B R, 23$ de marzo de 1897. 1892

19 $G R, 15$ de diciembre de $1886 ; B R, 23$ de junio de 1890, y $B R, 31$ de agosto de ${ }^{21} B R, 23$ de marzo de 1906. 
linderos, superficies o personas implicadas podía llegar a ser causa de paralización de los trámites. Así se comprueba, por ejemplo, en las dificultades para efectuar la anotación preventiva de embargo en el Registro de la propiedad o en la documentación generada por los diversos intentos de la Administración, incluso bien entrado el siglo $\mathrm{xx}$, de llevar adelante la incautación material de las fincas ${ }^{21}$.

Los textos presentan como algo habitual la existencia en muchos municipios de un cierto número de falsos contribuyentes que, figurando en los repartimientos como forma de aligerar el resto de las cuotas, hacían imposible, lógicamente, cualquier actuación administrativa destinada a ejecutar los débitos que fuese más allá de la adjudicación nominal a la Hacienda de una finca igualmente imaginaria ${ }^{22}$. El engaño podía ser continuado suponiendo a los falsos propietarios dueños de una parcela de terreno cualquiera, «incapaz de producto alguno por su extensión y calidad, por más que para los efectos de la imposición se le atribuyan grandes rendimientos», que acababa indefectiblemente adjudicada al Estado ${ }^{23}$.

Igualmente frecuentes fueron las denuncias sobre designaciones por parte de las juntas periciales de partidas fallidas arbitrarias e ilegítimas para beneficio de determinados contribuyentes, mientras en los mismos municipios, se decía, podía asistirse al embargo y a la ruina de muchos pequeños propietarios ${ }^{24}$. Sin embargo, desde las páginas del $B R$ se sostenía que en situaciones de crisis generalizada y de dificultades para cubrir el cupo del municipio, y como alternativa a una declaración masiva de fallidos que inevitablemente complicaría la gestión de los siguientes repartimientos anuales, desde los ayuntamientos se optaba por la estrategia de favorecer la adjudicación masiva de fincas a la Hacienda, aprovechando la incapacidad de ésta para hacerla efectiva desposeyendo de sus bienes a los propietarios deudores. Este argumento era presentado como una de las principales causas de la multiplicación de las adjudicaciones ${ }^{25}$. Por otro lado, la resistencia más o menos activa de las juntas periciales a declarar fallidos podía tener, en ocasiones, una motivación bienintencionada, usándose como una forma de retener los expedientes hasta la llegada de la cosecha

${ }^{21}$ Ministerio de Hacienda (1928).

${ }^{22} B R, 15$ de julio de 1908 .

${ }^{23} G R, 23$ de enero de 1889; GR, 29 de febrero de 1888, y $B R, 31$ de agosto de 1892.

${ }_{24} B R, 23$ de mayo de 1903, citando una noticia aparecida en la prensa de Cádiz. Informaciones similares referidas a Cartagena y Granada ( $B R, 15$ de noviembre de 1898), Sevilla ( $B R, 8$ de diciembre de 1898) o Véjer, Cádiz ( $B R, 31$ de julio de 1902).

${ }^{25}$ Por ejemplo, GR, 23 de enero de 1889. 
con la esperanza de disminuir así la cantidad de partidas finalmente incobradas ${ }^{26}$.

Otra de las dificultades con que tropezaban los agentes ejecutivos era la demora o denegación de la autorización de entrada en el domicilio de los deudores para proceder al embargo de muebles o ganado, algo que parece que fue habitual durante las resistencias generalizadas que provocaron las primeras medidas de Fernández Villaverde ${ }^{27}$.

Envolviendo todo el discurso, y en un tono regeneracionista característico de la época, los portavoces oficiosos de recaudadores y agentes denunciaban reiteradamente las actuaciones de carácter caciquil impulsadas por las autoridades locales: tratos de favor a familiares, arbitrariedad en la asignación de cuotas o, llegado el caso, la ejecución de fincas de escaso valor de ciertos propietarios pudientes como forma de enjugar deudas tributarias sin apenas pérdidas materiales ${ }^{28}$. La conclusión a la que se llegaba en las páginas del $B R$ no podía ser más explícita en cuanto a la necesidad de hacer la recaudación «independiente por completo de las Corporaciones populares, borrando toda tutela é intervención de las mismas y de los Alcaldes» ${ }^{29}$. Probablemente la conciencia de ese estado de cosas estaba en la base de medidas ministeriales que parecen tener un elevado componente punitivo contra las administraciones locales, como el decreto de la obligatoriedad para los ayuntamientos de aceptar la adjudicación a su nombre de las fincas de los deudores ejecutados, lo que suponía para los consistorios la asunción de los gastos del procedimiento y las cuotas futuras. La medida estuvo vigente entre el 5 de agosto de 1893 y el 30 de junio de 1895 , con nulo éxito y con la lógica oposición generalizada de los ayuntamien$\operatorname{tos}^{30}$. Atendiendo a la corriente de opinión favorable a la paulatina retirada de competencias a los alcaldes, la Instrucción de 1900 hizo el procedimiento en gran medida independiente de los poderes locales. Pero algunos pasos esenciales, como los trámites relacionados con la estadística territorial, quedaron todavía en sus manos. Ése fue un argumento más entre los utilizados por quienes demandaban un catastro parcelario que liberase a la Hacienda de las limitaciones impuestas por los amillaramientos.

${ }^{26} B R, 23$ de junio de 1890 .

${ }^{27} B R, 23$ de octubre de 1899.

${ }^{2 x} G R, 29$ de febrero de 1888, y GR, 23 de enero de 1889 . Tratos de favor a familiares en $B R, 28$ de febrero de 1890 .

${ }^{29} B R, 31$ de enero de 1898.

3.) Diario de Sesiones del Congreso, 22 de diciembre de 1894, p. 842. 


\subsection{La recaudación ejecutiva y el Registro de la propiedad}

La obligación para los agentes ejecutivos de adelantar los altos costes de la anotación preventiva de embargo en el Registro de la propiedad, que debía practicarse sobre las fincas a subastar para garantizar los derechos preferentes de la Hacienda pública, supuso un importante problema en zonas y momentos en que los embargos se contaban por decenas de miles ${ }^{31}$. El trámite, por otra parte, fue motivo de constantes encontronazos con los registradores de la propiedad ${ }^{32}$. El incumplimiento del plazo fijado para su formalización, quince días según la Instrucción de 1888, era una de las principales causas de malestar en los agentes. Para acelerar la celebración de las subastas, y a pesar del riesgo existente de causar la nulidad de todo el procedimiento, desde el $B R$ se llegaba a recomendar no esperar la devolución de la documentación procedente del Registro de la propiedad ${ }^{33}$.

La falta de datos, los errores en las descripciones y otros defectos de diversa índole en los expedientes provocaban la negativa de los registradores a practicar la anotación preventiva a nombre de la Hacienda, atendiendo a la imposibilidad de identificar las fincas sin margen para la duda. Dado que una gran mayoría de los deudores cuyos bienes se embargaban no presentaban sus titulos de propiedad al agente ejecutivo, la descripción de los inmuebles constituía el único indicio de que se disponía para localizarlos en los libros. La gran cantidad de fincas que a veces figuraban en los mandamientos colectivos de anotación («hemos visto uno en el que pasaban de 700») obligaba al registrador a un trabajo extra de búsqueda de las fincas y de sus historiales, operación que se encontraba entre las más «entretenidas y arriesgadas que puedan verificarse en la oficina de la que nos ocupamos» ${ }^{34}$. Otras cuestiones de carácter genérico, como la no obligatoriedad de la inscripción registral, las deficiencias de las antiguas contadurías o la inutilidad de los libros de embargos; o de tipo práctico,

${ }^{3 i}$ El gerente de la Sociedad Arrendataria de Contribuciones de Zaragoza veía imposible adelantar una cantidad que, a un promedio de dos pesetas por finca, superaba las doscientas mil pesetas $(B R, 8$ de marzo de 1902, pp. 70-71). Todavía en 1916, para afrontar el trámite «sería preciso que el Agente fuese un Roschild, y francamente, si así sucediese, nadie se ocuparía de un cargo que tantos sinsabores y disgustos lleva consigo" $(B R, 8$ de febrero de 1916). Idéntica queja en $G R, 8$ de abril de 1889.

${ }^{32} G R, 30$ de septiembre de 1887 , y $G R, 8$ de octubre de $1887 ; B R, 23$ de octubre de 1889 .

${ }_{33} B R, 8$ de marzo de 1900

${ }^{34}$ Los entrecomillados pertenecen a $G R, 30$ de septiembre de 1887. 
como la posibilidad o no de tramitar de forma conjunta los expedientes de varios deudores o el exceso de celo de los registradores en la demanda de datos de las fincas afectadas, motivaron repetidas quejas a lo largo de los años ochenta y noventa.

$\mathrm{Al}$ enorme volumen de trabajo se añadían las dificultades que los registradores encontraban para cobrar los honorarios a que daban lugar las transmisiones de propiedad cuando el pago debía efectuarlo el Estado, como sucedía cuando las fincas acababan siendo adjudicadas a la Hacien$\mathrm{da}{ }^{35}$. Ante este hecho, el propio $B R$, que propugnaba como alternativa un pago fijo por cada procedimiento individual independientemente de que los expedientes finalizasen con el cobro del débito o con la venta de las fincas, demostraba una cierta solidaridad con los registradores y entendía el que éstos recibiesen «de la peor manera» los mandamientos procedentes de los agentes ejecutivos ${ }^{36}$. Pero lo habitual era un ataque sin contemplaciones a la actitud obstruccionista con que el Registro de la propiedad despachaba los asuntos relativos a la recaudación, consecuencia de la «excesiva independencia de que alardean los Registradores y la tolerancia que se les dispensa por quien está encargado de hacerles cumplir con su deber» ${ }^{37}$. Recíprocamente, desde las instancias registrales se veían con reticencia «las invasiones» del ministerio de Hacienda en las competencias del de Gracia y Justicia, y se reclamaba un «deslinde completo de funciones y funcionarios» que acabase, por ejemplo, con la posibilidad de que en determinadas circunstancias los administradores subalternos de Hacienda, «que serán funcionarios muy dignos, pero que son de escasa categoría oficial», pudiesen multar a los registradores de la propiedad ${ }^{38}$.

\subsection{La recaudación ejecutiva y la administración de Hacienda}

En ocasiones también las propias administraciones provinciales de Hacienda suponían un obstáculo casi insalvable para recaudadores y agentes ejecutivos. La censura y, en su caso, la aprobación de los expedientes por ${ }^{35}$ Cuando eran rematadas, los derechos de los registradores se liquidaban a partir de
lo pagado por el comprador; si eran adjudicadas a la Hacienda, cosa «que ocurre en el 90 por 100 de los casos» habia que esperar «a que Hacienda quiera pagarlos, que no quiere nunca» $(B R, 23$ de octubre de 1889); también $B R, 9$ de marzo de 1897 .

3t $G R, 8$ de octubre de 1887 . En la misma línea, $G R, 23$ de diciembre de 1886, o $B R, 23$ de octubre de 1889.

${ }_{37} \mathrm{GR}, 31$ de mayo de 1885 .

"Citado en $B R, 8$ de enero de 1897 . 
parte de las Tesorerías provinciales eran imprescindibles para oficializar las partidas fallidas o conseguir la incautación material de las fincas adjudicadas a la Hacienda. La lenta verificación de los datos relativos a deudores y propiedades y la interminable comprobación de que el procedimiento se había ajustado a la normativa provocaban una completa parálisis administrativa que hacía casi imposible la conclusión de los procedimientos ${ }^{39}$.

Esta situación, que se añadía a las atávicas deficiencias de la maquinaria burocrática española, tenía como resultado la acumulación en los sucesivos presupuestos de una gran cantidad de cuotas incobrables por definición. En la documentación entregada a los recaudadores y agentes figuraban fallidos de años anteriores, duplicados, personas inexistentes, propietarios que habían dejado de serlo o fincas adjudicadas al Estado todavía no incautadas ${ }^{40}$. Este último caso venía a complicarse cuando el campesino había continuado trabajando las tierras que le habían sido embargadas en años anteriores. En tales circunstancias, frecuentes en las consultas dirigidas a las publicaciones especializadas, el agente ejecutivo ya no encontraba nada con lo cual afrontar, ya no el débito en cuestión, sino el simple inicio del procedimiento de apremio. Se recomendaba entonces actuar contra los frutos de la finca, recuperando así el espíritu de una ley fiscal que, en principio, consideraba a la renta de la tierra, y no su propiedad, el objeto imponible ${ }^{41}$. A pesar de ello no debieron de ser pocos los casos de fincas adjudicadas a la Hacienda un año tras otro, como argumentaban reiteradamente los gobiernos a la hora de justificar las altas cifras de subastas y adjudicaciones al Estado ${ }^{42}$.

El problema de los valores pendientes de liquidación, conocidos como «data interina» o «data provisional», llegó a alcanzar dimensiones gigantescas durante la gestión recaudatoria del Banco de España, entre 1868 y $1888^{43}$. Fueron necesarios varios años para regularizar la contabilidad de la Hacienda y la amenaza de una nueva «bola de nieve» descontrolada, formada por cuotas incobradas que cada año daban lugar a nuevos pro-

i4 GR, 31 de julio de 1884 .

(1) $B R, 23$ de enero de 1898, o BR, 15 de agosto de 1903 .

${ }^{41}$ La RO de 14 de julio de 1887 resolvia «que se halla obligado al pago de la contribución territorial el propietario de una finca aun cuando ésta sea adjudicada al Estado, mientras no tenga lugar la incautación por la Hacienda y el anterior propietario la posea» (Gaceta de Contribuciones, 15 de agosto de 1887).

42 GR, 15 de junio de 1887.

${ }^{43}$ Véase el cálculo realizado por Sánchez de Toca (1887, p. 251), alarmado por el volumen de la data interina y por la «gigantesca ejecución sin ejemplar quizás en ninguna nación antigua ó moderna» que representaba. 
cedimientos de apremio destinados a permanecer inconclusos, se mantuvo en el ambiente durante todo el período.

Parte de la responsabilidad en los problemas sufridos por la recaudación ejecutiva, incluyendo en ellos la indeseada multiplicación de las adjudicaciones de fincas a la Hacienda, era atribuida a la rigidez de las leyes y reglamentos del ramo de contribuciones. Sin embargo, las propuestas, de indudable carácter pragmático, que los representantes de la recaudación ejecutiva presentaban regularmente al ministerio de Hacienda eran, en su mayoría, sistemáticamente ignoradas. Así, junto a las peticiones de generosidad en el decreto de prórrogas y condonaciones en situaciones catastróficas, una de las demandas más repetidas era la de que se permitiese retrasar los apremios hasta la llegada de los períodos de recolección para poder aprovechar el momento de mayor liquidez monetaria de los campesinos ${ }^{t 4}$. Ante la presión de los plazos marcados por la Instrucción, que obligaba a muchos contribuyentes a ponerse en manos de la usura, no eran extrañas actitudes más flexibles por parte de ciertos recaudadores o agentes ejecutivos, con el riesgo consiguiente que suponía, en caso de impago, el haber tenido «esas consideraciones indebidas con los deudores» $y$ no haber seguido estrictamente el reglamento ${ }^{45}$.

El cierre de los expedientes era una condición indispensable para proceder a la liquidación de los gastos adelantados por los agentes ejecutivos durante el procedimiento, verdadero caballo de batalla en su relación con el Ministerio ${ }^{46}$. La devolución de ese capital, que condicionaba la supervivencia financiera del colectivo, no estaba prevista hasta la venta en subasta de las fincas afectadas o la formalización de la propiedad a nombre de Hacienda. De ahí la insistencia en la simplificación de los trámites como mejor forma de aligerar los procedimientos, solicitando, por ejemplo, la sustitución del expediente posesorio, contemplado por la Ley Hipotecaria para la inscripción de las fincas a nombre del Estado en el Registro de la propiedad, por una simple certificación de las Tesorerías de Hacienda que diese fe de la adjudicación. Con idéntica intención se reclamaba la adjudicación obligatoria de las fincas a los ayuntamientos, la regulación del arriendo de aquellas que ya estuviesen en plena posesión del Estado

${ }^{4}$ Por ejemplo: GR, 15 de junio de 1885 . Solicitud de prórrogas ante la pérdida total de las cosechas en Huesca $(B R, 23$ de abril de 1897) o por determinadas situaciones en Madrid y Zaragoza ( $G R, 31$ de julio de 1887 ).

${ }^{45} G R, 30$ de noviembre de 1890 . El recurso a la usura para el pago de contribuciones en Jaén: $G R, 15$ de abril de 1885 .

th $G R, 8$ de agosto de 1885 . Son innumerables las quejas que aparecen respecto a este tema en la GR o el $B R$. 
o la posibilidad de rematar los inmuebles por un importe equivalente al de los débitos adeudados, mucho más ventajoso para los potenciales compradores que su tasación oficial ${ }^{47}$. El colectivo de recaudadores y agentes ejecutivos se sentía, en definitiva, menospreciado por una Hacienda «que casi siempre da la razón á todos contra él y que á la vez de exigirle considerables ingresos entorpece los expedientes que son sometidos á su fallo, desestima sus justas quejas y reclamaciones y deja de pagarle los legítimos emolumentos de su trabajo» ${ }^{48}$.

Son abundantes, por lo tanto, los indicios que apuntan a una absoluta falta de coordinación, cuando no de mala fe, entre instituciones. «Cuestiones entre la Recaudación y los Registradores; cuestiones entre aquéllos y los Ayuntamientos; falta de auxilio de las Tesorerías» y pérdidas de tiempo desmoralizadoras «esperando el despacho de las certificaciones de fincas y de los Mandamientos de embargo» marcaban el trabajo cotidiano de recaudadores y agentes ${ }^{49}$. Frente a la incomprensión del resto de las instancias de la Administración, se cerraban filas en torno a la defensa corporativa del colectivo, adoptando a menudo un tono victimista que lamentaba amargamente la poca ayuda recibida y la escasa valoración pública de la profesión ${ }^{50}$. Esta última consideración parece estar de acuerdo con las también habituales quejas por la falta del personal suficiente para cubrir todas las zonas, lo que obligaba en ocasiones, y como ya se ha comentado, a dejar el servicio en manos de los ayuntamientos ${ }^{51}$.

Es casi innecesario decir, por otra parte, que la opinión sobre el cuerpo de recaudadores y, especialmente, el de agentes ejecutivos que se reflejaba en el resto de la prensa, incluso en aquella que se dirigía a los funcionarios de Hacienda, era totalmente diferente:

«¿Quién no ha visto Agentes ejecutivos que ostentan, posición social, y mayores medios de fortuna que el mismo Delegado de Hacienda de la provincia? El oro en dijes que adorna sus vestidos; el brillante necesario para deslumbrar á quienes no puedan conocer su origen; la cartera abierta

${ }^{47} G R, 15$ de junio de 1887. La adjudicación de las fincas a los ayuntamientos fue obligatoria entre 1893 y 1895 , la RO de 18 de octubre de 1887 reguló el arriendo de las fincas del Estado y el remate por débitos, recargos y costas funcionó, de facto, entre 1893 y 1897.

48 GR, 23 de junio de 1887.

t4 $B R, 8$ de agosto de 1901 .

"Según $G R, 23$ de junio de 1887, eran «pobres pigmeos» condenados «a pagar por todos, y, por consiguiente, á la miseria y á la ruina». En el mismo tono: $B R, 8$ de noviembre de 1899 , o $B R, 8$ de noviembre de 1900.

"1 GR, 15 de abril de 1885 , o $G R, 30$ de noviembre de 1889 . 
siempre para atender al obsequio, á la comodidad o al lujo con que satisfacen las necesidades del buen trato que les conviene sostener con los elementos afines y precisos á sus planes» ${ }^{52}$.

Muchas opiniones les atribuían gran parte de culpa por el estado de caos y paralización en que se encontraban los expedientes de fallidos y de adjudicación de fincas al Estado. La poca rigurosidad con que supuestamente cumplían trámites como las notificaciones a los deudores, el relleno de los impresos, el embargo de frutos y semovientes o las diligencias ante el Registro de la propiedad sólo producían, según sus críticos, montañas de expedientes destinados a quedar olvidados en las dependencias de las tesorerías de Hacienda ${ }^{53}$.

\subsection{La recaudación ejecutiva y el pequeño contribuyente rural}

Para explicar el aumento de la morosidad fiscal registrado en las últimas décadas del siglo XIX, al mal funcionamiento global de la Administración española había que añadir, en opinión de la comunidad de recaudadores $\mathrm{y}$ agentes ejecutivos, la actitud poco colaboradora de una gran parte de los contribuyentes. Dos lugares comunes resumen las denuncias: las prácticas caciquiles de los mayores contribuyentes y el problema de los «malos pagadores».

Ya hemos visto algunos de los mecanismos utilizados por las élites locales, fundamentados en su capacidad de control de los órganos políticos municipales, para eludir una parte importante de sus obligaciones fiscales ${ }^{54}$. Desde los escritos publicados en la GR o el BR se combatió en todo momento ese estado de cosas, defendiendo de forma vehemente la igualdad de trato a todos los contribuyentes ${ }^{55}$. La práctica habitual, sin embargo, no siempre se correspondía con ese principio teórico; las mismas publicaciones recogen indicios de determinados tratos de favor hacia «el rico contribuyente» también durante la fase ejecutiva ${ }^{56}$.

Por otra parte, bajo el calificativo de «malos pagadores» se hacía referencia tanto a los individuos que incumplían sus obligaciones con el fisco, como a provincias enteras. Demarcaciones como las de Cuenca, Málaga,

\footnotetext{
${ }_{52}^{52}$ La Hacienda Nacional, 1 de enero de 1902.

${ }_{53}$ La Hacienda Nacional, 8 de enero de 1902.

${ }^{5}$ La Hacienda Nacional, 15 de diciembre de 1909.

${ }^{5} \mathrm{BR}, 30$ de abril de 1890 .

$B R, 15$ de abril de 1885
} 
Almería, Huesca o Zaragoza eran propuestas como ejemplos de tradicional resistencia al pago de impuestos, mientras que en Girona, Barcelona o Madrid se daba por supuesta la presencia de un «excelente espíritu tributario» que daba lugar a una óptima práctica fiscal que se demostraba año tras año casi con independencia de la calidad de la acción de recaudadores y agentes ejecutivos ${ }^{57}$. Girona encarnaba el modelo idealizado de provincia cumplidora; en repetidas ocasiones mereció «especial mención por haberse hecho la liquidación sin que se haya presentado un solo recibo pendiente de cobro» ${ }^{58}$. Sus supuestas costumbres fiscales incluían el recurso de sus contribuyentes a pequeños créditos privados, a un interés inferior al que suponía el recargo de apremio, como forma de afrontar los pagos y evitar aparecer en las listas de morosos ${ }^{59}$.

La actitud de los responsables de la recaudación respecto al pequeño contribuyente rural, por lo general alejado de los mecanismos fraudulentos utilizados por los más influyentes, oscilaba entre un rancio paternalismo que asumía su ignorancia y miseria, y el temor que propiciaban los numerosos incidentes que tenían a recaudadores y agentes como víctimas. Pero junto a esa mezcla de prejuicios existió también, por lo menos en determinados momentos, casi siempre coincidentes con gobiernos de color liberal, una clara conciencia de la poca capacidad, legislativa y humana, de la Administración para vencer la distancia que la separaba de una parte muy importante de los contribuyentes ${ }^{60}$. Una incomprensión recíproca que estaba en la raíz de «la lucha abierta, la desconfianza mutua, la enemistad manifiesta entre el contribuyente y el Fisco» y que constituia uno de los problemas endémicos de España ${ }^{61}$. Si para algún articulista las causas de esa realidad había que buscarlas en los «abusos inveterados del antiguo régimen», el aumento desproporcionado de las contribuciones, los favoritismos en el reparto de cargas y, sobre todo, «el abandono lastimoso en que se hallan los servicios que deberían constituir la recompensa y premio de los sacrificios cada día mayores que se exigen al contribuyente», para otros la situación no era más que el reflejo de una cultura del fraude ampliamente generalizada y socialmente tolerada ${ }^{62}$.

${ }^{57} B R, 15$ de febrero de 1905 , o $G R, 31$ de julio de 1886 .

s8 $G R, 31$ de julio de 1886 .

"9 $B R, 30$ de noviembre de 1908 .

*) $G R, 23$ de junio de 1887 .

6) $G R, 23$ de agosto de 1888 . de 1892.

12 La primera postura en $G R, 23$ de agosto de 1888; la segunda en $B R, 30$ de noviembre 
Por lo que respecta al ámbito de la recaudación ejecutiva, algunas de las estrategias más habituales destinadas a complicar el avance del procedimiento, dejando a un lado las manifestaciones de violencia individual o colectiva, eran, según los agentes ejecutivos, la «confabulación» de los pueblos para dejar sin efecto las subastas de fincas, presionando a los posibles compradores para que renunciasen a pujar por ellas; la acción de los depositarios de los efectos embargados dirigidas a entorpecer o impedir los trámites, por ejemplo, no presentándose a los actos de subasta; la simple ausencia de los deudores; o la resistencia a abandonar las casas objeto de desahucio ${ }^{63}$.

Por otra parte, la demora en la incautación efectiva de las fincas adjudicadas a la Hacienda, se argumentaba, constituía un mal ejemplo para los contribuyentes, quienes preferían arriesgarse a sufrir el embargo de una finca a tener que recurrir a la usura o a afrontar la pérdida de otros bienes o animales que, en su situación, les eran imprescindibles ${ }^{64}$. La única solución, se repetía insistentemente, consistía en consolidar la ilusoria propiedad que Hacienda ejercía sobre decenas de miles de fincas expulsando definitivamente a sus antiguos propietarios mediante el uso de todos los medios legales y policiales. Medidas como las que facilitaban el retracto, es decir, la recuperación por parte de los deudores, familiares o dueños de fincas colindantes de las propiedades expropiadas, eran muy a menudo criticadas por ser consideradas excesivamente ventajosas, un agravio para quienes cumplían con las obligaciones tributarias y una burla para la Administración, especialmente cuando los deudores habían seguido cultivando «tranquilamente» sus tierras ${ }^{65}$.

Todos esos razonamientos eran usados por quienes, desde instancias oficiales, respondían a la alarma creada por las cifras de embargos y subastas y a las denuncias sobre las supuestas dificultades que una excesiva carga fiscal provocaba sobre la propiedad territorial ${ }^{66}$. Pero la atribución exclusiva de la sensación de crisis imperante a la mala fe de los con-

${ }^{\text {63 }}$ La confabulación de los pueblos en $G R, 31$ de octubre de 1886; $G R, 8$ de noviembre de 1886, o $B R, 8$ de marzo de 1890. La incomparecencia de depositarios y deudores en $G R, 31$ de marzo de 1887; GR, 31 de julio de 1887, o $G R, 15$ de septiembre de 1886. ${ }^{64} B R, 23$ de marzo de 1897 . Las consecuencias del «mal ejemplo» en $B R, 8$ de agosto
de $1897 ; G R, 15$ de junio de $1885 ; B R, 8$ de marzo de 1890 , y en el informe del Tribunal de cuentas reproducido en $B R, 31$ de julio de 1900 . Nacional, 23 de abril de 1902). También: GR, 31 de julio de 1888 , o BR, 15 de abril
de 1892 . de 1892 .

th $B R, 15$ de junio de 1898 . 
tribuyentes y a la deficiencia de las estadísticas puede ser matizada, si no desmentida, por algunos argumentos presentes de forma implícita en las propias publicaciones destinadas a recaudadores y agentes. Así, algunas de las cifras oficiales o las numerosas consultas dirigidas al $B R$ en torno a la problemática que comportaba el traspaso de las propiedades cuando había tenido lugar su venta en alguna de las subastas celebradas indican que el embargo de una finca implicaba para el deudor un riesgo real de perder la propiedad de la misma ${ }^{67}$. Igualmente, la conflictividad antifiscal, en aumento durante los años ochenta y noventa del siglo $\mathrm{XIX}, \mathrm{y}$ a menudo relacionada con los intentos de embargo motivados por el impago de algún impuesto, parece contradecir la idea de una actitud indolente o resignada por parte de los contribuyentes. Por otra parte, en las páginas de la $G R$ o del $B R$ abundan los testimonios de recaudadores y agentes ejecutivos sobre la precaria situación económica de la población rural, presentada, uria vez más, como un factor externo a su trabajo que venía a exculparles de los descensos en las recaudaciones y cuyo síntoma eran, precisamente, la desmedida cantidad de fincas embargadas y subastadas en algún partido judicial o municipio ${ }^{68}$.

\section{CONCLUSIÓN}

Los textos publicados en la prensa dirigida al colectivo encargado de la recaudación de contribuciones, en un esfuerzo continuado por demostrar que el aumento de la morosidad que aparentemente se estaba produciendo durante los últimos decenios del siglo XIX no era atribuible a defectos de organización o al desinterés de recaudadores y agentes ejecutivos, nos proporcionan una descripción pormenorizada de los comportamientos de instituciones, colectivos o individuos en su relación cotidiana con el fisco, así como diversas informaciones sobre algunas de las consecuencias más dramáticas del sistema, como fueron los embargos de fincas por deudas tributarias o la conflictividad social relacionada con la fiscalidad. La impresión que obtenemos de su lectura es la de unos procedimientos administrativos extremadamente rígidos y fácilmente obstaculizables que si ya se mostraban de escasa utilidad para afrontar situaciones concretas, como las derivadas de una plaga o de una tormenta,

67 Véase la nota 7.

6\% Por ejemplo, BR, 30 de junio de 1897; GR, 15 de marzo de 1886, o GR, 31 de marzo de 1887. 
quedaron ampliamente desbordados por la generalización de la crisis agraria finisecular.

La recaudación ejecutiva fue capaz de iniciar millones de expedientes de apremio pero tuvo enormes dificultades para cerrarlos de manera satisfactoria. El absoluto desconocimiento estadístico sobre esta cuestión, la impotencia evidente exhibida frente a las actitudes entorpecedoras de los grupos de poder municipales, en contraste con el rigor implacable en el trato con los pequeños contribuyentes, o la problemática coordinación entre las distintas esferas de la Administración en lo que respecta a la gestión tributaria, aspectos de los cuales los testimonios de recaudadores y agentes ejecutivos dan buena fe, son indicios de una administración de Hacienda permanentemente inacabada en su vertiente legislativa y excesivamente burocratizada y alejada de la realidad en sus ramificaciones más cercanas al contribuyente.

Aunque no pueden descartarse «epidemias» de morosidad fiscal favorecidas en ciertos momentos por factores diferentes a la falta de medios económicos para afrontar el pago, parece difícil desmentir la trascendencia que para cientos de miles, quizás millones, de contribuyentes tuvo el hecho de ver sus propiedades embargadas y puestas a la venta en subasta pública. Las innumerables fincas adjudicadas a la Hacienda, que tantos problemas de gestión provocaron y cuya expropiación efectiva hubiese dado lugar a una enorme convulsión social, constituyeron uno de los indicadores más claros del agotamiento del modelo tributario por entonces vigente y de las dificultades del Estado para ofrecer soluciones satisfactorias a los problemas originados por los cambios económicos y sociales que el campo español estaba experimentando en las décadas finales del siglo XIX.

\section{BIBLIOGRAFÍA}

Calatayud Giner, Salvador (1989): Capitalismo agrario y propiedad campesina. La Ribera del Xúquer, 1860-1930, Valencia, Edicions Alfons el Magnànim.

Comin, Francisco (1988): Hacienda y Economía en la España contemporánea (1800-1936), 2 vols., Madrid, IEF.

Crisis agricola y pecuaria, la (1887-1889): Madrid, Tipografía de los "Sucesores de Rivadeneyra", 8 vols.

Díz Marin, Pedro (2000): «Oligarquía y fiscalidad: los primeros pasos de la contribución de inmuebles, cultivo y ganadería en la provincia de Alicante», Revista de Historia Económica, núm. 2, pp. 309-338.

Fontana, Josep (1975): Cambio económico y actitudes politicas en la España del siglo XIX (2. ${ }^{\text {a }}$ ed. rev.), Esplugues de Llobregat, Ariel. 
GaRRABOU, Ramon (1975): «La crisi agrària espanyola de finals del segle XIX: una etapa del desenvolupament del capitalisme», Recerques, núm. 5, pp. 163-216.

Garrabou, Ramon; Planas, Jordi, y Saguer, Enric (2001): Un capitalisme impossible? La gestió de la gran propietat agrària a la Catalunya contemporània, Vic, Eumo.

Germán, Luis, y ForCADELL, Carlos (1988): «La crisis fínisecular en la agricultura interior: el caso de Aragón», en Ramón GARRABOU (ed.), La crisis agraria de fines del siglo XIX, Barcelona, Crítica, pp. 69-93.

GirAlT, Emili (1990): «Tradició i innovació en l'agricultura del segle XIX», en VVAA, Historia econòmica de la Catalunya contemporània s. XIX, vol. 2, Barcelona, Fundació Enciclopèdia Catalana, pp. 121-305.

López Estudillo, Antonio (2000): «Reflexiones sobre las posibilidades de empleo de la documentación fiscal para el análisis histórico. Las cartillas evaluatorias», Seminario Internacional Fuentes y métodos para la bistoria rural (ss. XVIIl-XX. Contar, representar, interpretar. Bases de datos y análisis histórico, Córdoba.

MALLADA, Lucas (1969): Los males de la patria y la futura revolución española, Madrid, Alianza (1." ed., 1890).

Martorell Linares, Miguel Ángel (2000): El santo temor al déficit, Madrid, Alianza Editorial.

Ministerio de Hacienda (1928): Memorias de las Direcciones Generales y Servicios Centrales del Departamento acerca de la gestión económico-administrativa realizada durante los años 1926 y 1927, Madrid, Imprenta de la Fábrica Nacional de Moneda y Timbre.

Pan-Montojo, Juan (1994): «Lógica legal y lógica social de la contribución de consumos y los derechos de puertas», en El fraude fiscal en la Historia de España. Hacienda Pública Española. Monografia, 1/1994, pp. 217-229.

Pascun I Domenech, Pere (2000): Els Torelló. Una familia igualadina d'advocats $i$ propietaris, 2 vols., Barcelona, Fundació Salvador Vives i Casajuana.

PAZOS Y GARCIA, Diego (1908): La cuestión agraria de Irlanda y referencias a la de España, Madrid, Establecimiento tipográfico de Jaime Ratés Martín.

Pérez PICAzo, Maria Teresa (1996): Historia de España del siglo xx, Barcelona, Crítica.

PRo Rurz, Juan (1994): «El poder de la tierra: una lectura social del fraude en la contribución de inmuebles, cultivo y ganadería (1845-1936)», en El fraude fiscal en la Historia de España. Hacienda Pública Española. Monografia, 1/1994, pp. 189-201.

SÁnchez AsEnsio, M. (1926): Las cuestiones triguera y ganadera en España, Toledo, Sebastián Rodríguez, Impresor.

SÁNCHEZ DE TOCA, Joaquín (1887): «Apreciación de la crisis agraria por la diferencia entre el precio natural de la producción y las cotizaciones del mercado», Revista Contemporánea, LXVI, pp. 251-252.

VALLEJO, Rafael (1996): «El impuesto de consumos y la resistencia antifiscal en la España de la segunda mitad del siglo xux: un impuesto no exclusivamente urbano», Revista de Historia Económica, núm. 2, pp. 339-370.

- (1998): Reforma tributaria y fiscalidad sobre la agricultura y la propiedad en la España liberal, 1845-1900, Santiago de Compostela, tesis doctoral en CD-ROM, Servicio de Publicacións e Intercambio Científico da Universidade de Santiago. 
-- (1999): «La Hacienda española durante la Restauración (1875-1900): ¿quietismo fiscal?», en F. Comin Comin y M. A. Martorell Linares (eds.), Villaverde en Hacienda, cien años después, Hacienda Pública Española, número monográfico, pp. 47-71.

- (2001): Reforma tributaria y fiscalidad sobre la agricultura en la España liberal, 1845-1900, Zaragoza, Prensas Universitarias de Zaragoza. 